\title{
Cannabinoid receptor gene polymorphisms and cognitive performance in patients with schizophrenia and controls
}

\author{
Rodrigo Ferretjans, ${ }^{1}$ (iD Renan P. de Souza, ${ }^{2}$ (iD Bruna Panizzutti, ${ }^{3,4}$ (iD Pâmela Ferrari, ${ }^{5,6}$ \\ Lucas Mantovani, ${ }^{1}$ iD Salvina M. de Campos-Carli, ${ }^{1}$ Rafael R. Santos, ${ }^{1}$ Fernanda C. Guimarães, \\ Antonio L. Teixeira, ${ }^{7,8}$ (iD Clarissa S. Gama, ${ }^{4,5}$ (iD João V. Salgado ${ }^{1,9}$ (iD \\ ${ }^{1}$ Programa Interdisciplinar de Pós-Graduação em Neurociências, Instituto de Ciências Biológicas, Universidade Federal de Minas Gerais \\ (UFMG), Belo Horizonte, MG, Brazil. ${ }^{2}$ Programa de Pós-Graduação em Genética, Instituto de Ciências Biológicas, UFMG, Belo Horizonte, \\ MG, Brazil. ${ }^{3}$ The Institute for Mental and Physical Health and Clinical Translation, Deakin University, Barwon Health, Geelong, Australia. \\ ${ }^{4}$ Centre for Molecular and Medical Research, School of Medicine, Deakin University, Geelong, Australia. ${ }^{5}$ Programa de Pós-Graduação em \\ Psiquiatria e Ciências do Comportamento (PPGPSIQ), Universidade Federal do Rio Grande do Sul (UFRGS), Porto Alegre, RS, Brazil. \\ ${ }^{6}$ Laboratório de Psiquiatria Molecular, Centro de Pesquisa Experimental, Hospital de Clínicas de Porto Alegre (HCPA), Porto Alegre, RS, \\ Brazil. ${ }^{7}$ Instituto de Ensino e Pesquisa, Santa Casa BH, Belo Horizonte, MG, Brazil. ${ }^{8}$ Neuropsychiatry Program, UTHealth Houston, TX, USA. \\ ${ }^{9}$ Departamento de Morfologia, Instituto de Ciências Biológicas, UFMG, Belo Horizonte, MG, Brazil.
}

\begin{abstract}
Objective: To test the hypothesis that genetic variations of cannabinoid receptors contribute to the pathophysiology of cognitive deficits in schizophrenia.

Methods: In this genetic association case-control study, cannabinoid receptor polymorphisms CNR1 rs12720071 and CNR2 rs2229579 were tested for association with neurocognitive performance in 69 patients with schizophrenia and 45 healthy controls. Neurocognition was assessed by the Brief Assessment of Cognition in Schizophrenia (BACS).

Results: We found a consistent association between CNR1 rs12720071 polymorphism and the cognitive performance of patients in several cognitive domains. Patients with $\mathrm{C} / \mathrm{C}$ polymorphism presented significantly worse performance in motor speed, verbal fluency, attention/processing speed and reasoning/problem solving.

Conclusion: Although limited, our data support the hypothesis that CNR1 variations may be associated with the pathogenesis of cognitive deficits of schizophrenia.
\end{abstract}

Keywords: Schizophrenia; cognitive dysfunction; cannabinoids; endocannabinoids; CNR1; CNR2

\section{Introduction}

Schizophrenia, a chronic psychiatric syndrome that affects approximately $1 \%$ of the world population, involves highly heterogeneous etiological, neurobiological, and clinical aspects and is associated with varying degrees of functional and social impairment. As a result, schizophrenia is a major cause of disability worldwide. ${ }^{1,2}$

Multiple genetic and environmental factors interact with each other and with neurodevelopment mechanisms to cause the disease. ${ }^{3}$ The major role played by genetic factors in schizophrenia is reflected by the disorder's high heritability, approximately 60 to $80 \% .{ }^{4}$ The genetic architecture of schizophrenia is complex, heterogeneous, and polygenic, with risk given by a myriad of common single nucleotide polymorphisms (SNPs), each with very small individual effects, and unusual, but highly penetrating, genetic variants of great effect. ${ }^{5-7}$ Evidence suggests that "schizophrenia genes" do not encode schizophrenia

Correspondence: João Vinícius Salgado, Instituto de Ciências Biológicas, Departamento de Morfologia, Universidade Federal de Minas Gerais, Av. Antônio Carlos, 6627, Campus Pampulha, CEP 31270-910, Belo Horizonte, MG, Brazil.

E-mail: jvisal@gmail.com

Submitted Nov 21 2020, accepted Feb 20 2021, Epub Jun 232021. per se, but rather broader clinical constructs such as positive and negative symptoms or neurocognitive deficits. ${ }^{8}$ To reduce the "noise" that phenotypic heterogeneity brings to genetic studies, research efforts have been redirected to the recognition of endophenotypes, ${ }^{9}$ i.e., biological traits that are disease-related but state-independent and closer to genetic determinants than the complete behavioral phenotype. ${ }^{10,11}$

Cognitive deficits have been proposed as endophenotypes of schizophrenia. ${ }^{12}$ These stable, persisting deficits strongly predict unfavorable functional outcomes, ${ }^{13,14}$ are highly heritable ${ }^{14}$ and can be found in attenuated forms in first-degree healthy relatives. They are also presumably genetically simpler than the behavioral phenotype and can be reliably measured. ${ }^{15}$

Several lines of evidence implicate the endocannabinoid system (EcS) in the pathophysiology of schizophrenia (for a review, see Ferretjans et al. ${ }^{16}$ ). The EcS is involved in lipid neuromodulation ${ }^{17}$ and plays an important role in

How to cite this article: Ferretjans R, de Souza RP, Panizzutti B, Ferrari P, Mantovani L, de Campos-Carli SM, et al. Cannabinoid receptor gene polymorphisms and cognitive performance in patients with schizophrenia and controls. Braz J Psychiatry. 2022;44:26-34. http://dx.doi.org/10.1590/1516-4446-2020-1650 
central nervous system (CNS) processes, such as neurodevelopment, ${ }^{18}$ regulation of neurotransmission, ${ }^{19}$ and synaptic plasticity. ${ }^{20,21}$ Endocannabinoids act by interacting with specific receptors. Cannabinoid receptor type 1 (CB1R) is expressed in greater quantity in the CNS. The gene encoding CB1R (CNR1), located in chromosome 6 (6q14-q15), contains at least four exons, spans $25 \mathrm{~kb}$, and has five isoforms. ${ }^{22,23}$ Conversely, expression of cannabinoid receptor type 2 (CB2R) is less common in the CNS, occurring mainly in tissues and peripheral immune cells. ${ }^{24}$ Its gene (CNR2) is located in chromosome 1 (1p35-p36.1) and contains three exons alternatively transcribed and spliced to yield two isoforms. ${ }^{22,25}$

Genetic variants of cannabinoid receptors have been associated with cognitive performance. A reduction in $\mathrm{P} 300$ wave amplitude was found in alcohol users homozygous for the CNR1 (AAT)n repetition polymorphism. ${ }^{26}$ Similar results were observed in healthy individuals who were exposed to cannabis, which suggests involvement of CB1R in neural mechanisms related to attention and working memory. ${ }^{27} \mathrm{CNR} 1$ gene polymorphisms ([AAT]n variants and rs2180619) have been associated with lower efficiency of working memory, attentional processing and procedural learning. ${ }^{28-31}$ Besides, an interaction between CNR1 rs1406977 polymorphism and cannabis use was associated with prefrontal cortex connectivity ${ }^{32}$ and activity ${ }^{33}$ during working memory performance in healthy subjects. Finally, cannabis use seems to change the relationship between co-expression of a gene network involved in endocannabinoid signaling and the efficiency of information processing in neural networks that underlie the cognitive processes involved in working memory in healthy subjects. ${ }^{34}$ In healthy subjects, CNR1 variations have been shown to increase the risk of experiencing psychotic symptoms after using marijuana, ${ }^{35}$ and a locus in CNR2 was associated with distressing psychotic experiences in the general population. ${ }^{36}$ Two studies have evaluated the possible influence of cannabinoid receptor polymorphisms on the cognitive performance of patients with schizophrenia. In the first study, three CNR1 SNPs (including rs12720071) were associated with worse cognitive performance and lower volume of white matter in patients with schizophrenia. ${ }^{37}$ In the second study, the CNR1 rs7766029 polymorphism was associated with higher improvement in verbal memory and attention after 18 months of treatment. ${ }^{38}$

Therefore, the evidence suggests that genetic variations of cannabinoid receptors may contribute to the pathophysiology of cognitive deficits in schizophrenia. To investigate this hypothesis, we performed a genetic association casecontrol study, in which alleles and genotypes of one CNR1 polymorphism and one CNR2 polymorphism were tested for association with neurocognitive performance in patients with schizophrenia and healthy controls.

\section{Methods}

\section{Subjects}

Two separate, unrelated samples were recruited, comprising 69 patients with schizophrenia and 45 healthy controls. Cases were recruited in two outpatient clinics (Schizophrenia Outpatient Clinic at a teaching hospital, Instituto Raul Soares/Fundação Hospitalar do Estado de Minas Gerais, and Mental Health Outpatient Clinic in Nova Lima, state of Minas Gerais), and controls were recruited through advertisements in the community. The inclusion criteria for patients were: 1) diagnosis of schizophrenia according to DSM-IV criteria ${ }^{39}$ confirmed by the Mini International Neuropsychiatric Interview (MINI-plus) ${ }^{40,41}$; 2) age between $18-60$ years; 3) clinical stability. Controls were included if they were between 18-60 years of age and presented no criteria for current psychiatric disorder, as confirmed by the MINI-plus.

\section{Assessment procedures}

\section{Clinical assessment}

Sociodemographic and clinical data were collected through a semi-structured clinical interview by trained research team members. Positive and negative symptoms were assessed using the Positive and Negative Syndrome Scale (PANSS). ${ }^{42}$ Clinical stability was defined as a PANSS positive score of 19 or less (and less than 4 in any item of the positive scale).

\section{Cognitive assessment}

Cognitive assessment was performed using the Brief Assessment of Cognition in Schizophrenia (BACS). ${ }^{43}$ This battery was proposed to cover the major cognitive domains affected in schizophrenia: verbal memory (word list test); operational memory (digit sequencing test); motor speed (token motor task); verbal fluency (semantic or categorical fluency and phonetic or letter fluency); attention and speed of information processing (symbol coding task); and reasoning and problem solving (Tower of London task). Higher scores indicate better performance in specific skills. A composite score (BACS composite) was calculated from the mean of the normalized scores ( $\mathrm{z}$ score, with mean $=0$ and standard deviation $[S D]=1$ ) of the six individual BACS tests (according to, ${ }^{43}$ page 287). Normalized scores were drawn from a validated Brazilian Portuguese version of BACS. ${ }^{44}$

\section{Genetic analysis and genotyping}

Patients and controls had $5 \mathrm{ml}$ of blood collected by venipuncture, using EDTA vacuum tubes and stored at $-20{ }^{\circ} \mathrm{C}$ until analysis. Genotyping experiments were performed at the Molecular Psychiatry Laboratory at Hospital de Clínicas de Porto Alegre (HCPA)/Universidade Federal do Rio Grande do Sul (UFRGS), and all materials and reagents were used as per manufacturers' recommendations. Genomic DNA was extracted using a commercial kit (Illustra Blood genomic prep, GE Healthcare 28-9042-64, GE Healthcare, Little Chalfont, Amersham, UK). The kit promotes binding of the desired nucleic acid to a silica membrane; once the DNA binds to the membrane, a series of washes are performed to 
remove contaminants. In the last step of the protocol, the DNA is eluted with nuclease free water. The amount and purity of the obtained genomic DNA were evaluated by spectrophotometry in Nanodrop (260/280 and 260/230). All DNA samples were diluted and standardized to $1 \mathrm{ng} / \mu \mathrm{l}$ of DNA. For the PCR preparation, $5 \mu \mathrm{l}$ of Master MixTaqMan (4371353, Applied Biosystems, Carlsbad, CA, USA), $3.5 \mu \mathrm{l}$ of nuclease free water, $0.5 \mu \mathrm{l}$ of assay available for each SNP analysis, and $1 \mu$ l of DNA sample were used, on the Applied Biosystems 7500 Real-Time PCR Systems (Applied Biosystems, Carlsbad, CA, USA). Genotyping of the cannabinoid receptor polymorphisms was performed using a 5' nuclease TaqMan allelic discrimination assay: TaqMan ${ }^{\circledR}$ SNP Genotyping assay rs12720071 (for CNR1) and rs2229579 (for CNR2) from Applied Biosystems (by Life Technologies, Carlsbad, CA, USA).

Polymorphisms rs12720071 and rs2229579 were chosen based on the evidence of both possible involvement with the risk of schizophrenia and possible contribution to the genesis of cognitive deficits. CNR1 polymorphisms have been associated with structural changes in $\mathrm{CNS},{ }^{45}$ and lower white matter volume and worse cognitive performance. ${ }^{37}$ In turn, only contradictory evidence is available regarding association of CNR2 SNP rs2229579 with schizophrenia (a positive and a negative result), and its relation with cognitive performance has not yet been tested. CNR1 rs12720071 ( $\mathrm{T}>\mathrm{C}$ ) polymorphism has two alleles ( $T$ and $C$ ) and three possible genotypes ( $T / T$, $\mathrm{T} / \mathrm{C}$ and $\mathrm{C} / \mathrm{C}$ ), while $C N R 2$ rs2229579 $(G>A)$ polymorphism has $G$ and $A$ alleles and the $G / G, G / A$ and $A / A$ genotypes.

\section{Statistical analysis}

Continuous variables were expressed as means and standard deviation or medians and range of variation, as appropriate. Categorical variables were expressed as proportions. Normal distribution of variables was assessed by the Kolmogorov-Smirnov test. Genotypic distribution, allelic frequency and Hardy-Weinberg equilibrium (HWE) were calculated by the chi-square test. Comparison between groups was performed by $t$ test or Mann-Whitney test, as appropriate, and comparisons between two categorical variables were performed by chi-square test or Fisher's exact test, as appropriate. Effect sizes were expressed by Cohen's $d$. Alpha was set at 0.05 and the correction for multiple tests was done by the Bonferroni method (according to the following description: 2 polymorphisms $\times 5$ genetic models $=10$ comparisons; $\mathrm{p}$ corrected for multiple comparisons = $0.05 / 10=0.005$ )

Association analysis between polymorphisms and neurocognitive performance was performed using different genetic models (codominant, dominant, recessive, superdominant, and additive). To control the possible confounding effect of intervenient variables on patients' cognitive performance, we performed a multiple linear regression, in which cognitive performance was entered as a dependent variable, the genotype as an independent variable, and possible confounding variables (use of cannabis, age of onset, time of illness, education level and medication, namely antipsychotics and anticholinergics) as covariates. To evaluate if there was an interaction effect between the group (schizophrenia vs. control) and the genotype on cognitive performance, we performed a two-way analysis of variance (ANOVA), in which cognitive performance was the dependent variable and the genotype (3 groups) and group (patients vs. controls) were independent factors. All analyses were performed using the SPSS version $20,{ }^{46}$ or R Software. ${ }^{47}$

\section{Ethics statement}

The study was approved by the local ethics research committee and all participants signed an informed consent form.

\section{Results}

\section{Descriptive analysis}

Descriptive data are presented in Table 1. There was no difference between the mean ages of patients and controls (39.9 vs. 41.5 years respectively, $p=0.47$ ). However, the patient group included a higher proportion of women (38 vs. $16 \%, p=0.02$ ) and had lower educational level than controls (7.7 vs. 10.5 years of study respectively, $p<0.01$ ).

As expected, cognitive performance was significantly lower in patients than controls for all individual domains and for the BACS global score $(p<0.01)$. Patients presented overall cognitive performance on average 1.44 standard deviation below the normative sample. As for individual cognitive domains, the highest differences were found in the attention domains (Cohen's $d=2.7$ ), motor speed (Cohen's $d=2.3$ ), and overall cognitive performance (Cohen's $d=2.2$ ). One third of patients had mild or nonexistent cognitive deficits (up to 1 SD below the normative sample), while two thirds had significant deficits (equal or above $1 \mathrm{SD}$ below the normative sample).

Allelic and genotypic distribution of the polymorphisms tested are described in Table 2. The genotypic distribution in controls did not deviate from that expected by the HWE.

\section{Cannabinoid receptor 1 (CNR1) rs12720071 polymorphism and cognitive performance}

CNR1 rs12720071 ( $\mathrm{T}>\mathrm{C}$ ) polymorphism was significantly associated with patient performance in several cognitive domains. For the working memory domain (Table 3), C/C and T/T patients had worse performance than $\mathrm{C} / \mathrm{T}$ patients (mean [standard error] $=8^{3}$ vs. 8.7 [1.1] $\times 13.2$ [0.6], respectively; $p<0.005$, significant after correction for multiple comparisons). In addition, $\mathrm{C}$ allele carriers $(\mathrm{T} / \mathrm{C}$ and $\mathrm{C} / \mathrm{C}$ ) performed better than $\mathrm{T} / \mathrm{T}$ carriers (mean [standard error] $=12.8$ [0.6] vs. 8.7 [1.1], $p<$ 0.005). For the motor speed domain (Table 3), C/C patients had significantly lower performance than T allele carriers (mean [standard error] $=21$ [10.5] vs. 49.6 [2.1], 
Table 1 Descriptive data of the sample

\begin{tabular}{|c|c|c|c|c|}
\hline & Patients $(n=69)$ & Controls $(n=43)$ & $\mathrm{p}$-value & Cohen's $d$ \\
\hline \multicolumn{5}{|l|}{ Sociodemographic data } \\
\hline Age (years) & $39.9(11.8)$ & $41.5(10.5)$ & 0.47 & - \\
\hline Gender, n (\%) & & & $0.02 *$ & - \\
\hline Female & $26(38)$ & $7(16)$ & & - \\
\hline Male & $43(62)$ & $36(84)$ & & - \\
\hline Education (years) & 7.7 (3.9) & $10.5(3.1)$ & $<0.01^{\star \star}$ & - \\
\hline \multicolumn{5}{|l|}{ Clinical data } \\
\hline Age at onset & $27.3(11.1)$ & - & - & - \\
\hline Years of disease & $12.4(10.1)$ & - & - & - \\
\hline Medication (CPMZ equivalent) & 347.4 (205.3) & - & - & - \\
\hline PANSS & & - & - & - \\
\hline Positive & $9.7(3)$ & - & - & - \\
\hline Negative & $17.5(6.5)$ & - & - & - \\
\hline General & $26.3(7.3)$ & - & - & - \\
\hline Total & $53.4(13.6)$ & - & - & - \\
\hline Tobacco use, n (\%) & $22(32)$ & $5(11.1)$ & $0.01^{\star \star}$ & - \\
\hline Cannabis use, $n(\%)$ & $12(17.4)$ & $0(0)$ & $<0.01^{\star *}$ & - \\
\hline \multicolumn{5}{|l|}{ Cognitive performance } \\
\hline BACS & & & & - \\
\hline Verbal memory & $26.4(9.7)$ & $36.9(9.6)$ & $<0.01^{\star *}$ & 1.5 \\
\hline Working memory & $11.8(4.9)$ & $15.7(4.9)$ & $<0.01^{\star *}$ & 0.8 \\
\hline Motor speed & $47.9(18.5)$ & 77.8 (16.4) & $<0.01^{\star \star}$ & 2.3 \\
\hline Verbal fluency, semantic & $13.2(4.7)$ & $19(4.3)$ & $<0.01^{* *}$ & 3.9 \\
\hline Verbal fluency, category (letter F) & $8.3(4.1)$ & $11.8(4.6)$ & $<0.01^{* *}$ & 3.8 \\
\hline Verbal fluency, category (letter S) & $7.4(3.6)$ & $11.4(4.1)$ & $<0.01^{\star *}$ & 1.0 \\
\hline Verbal fluency, total & $28.9(11)$ & $42.1(10.5)$ & $<0.01^{\star *}$ & 1.8 \\
\hline Attention & $22.8(12.1)$ & $39.2(14.6)$ & $<0.01^{\star \star}$ & 2.7 \\
\hline Reasoning and problem solving & $10.8(5.8)$ & $14(5.8)$ & $<0.01^{\star *}$ & 1.8 \\
\hline Composite score $(z)$ & $-1.44(0.9)$ & $-0.2(0.8)$ & $<0.01^{\star *}$ & 2.2 \\
\hline Cognitive category, $\mathrm{n}(\%)$ & & & $<0.01^{\star \star}$ & - \\
\hline$<1 \mathrm{SD}$ & 23 (33.3) & $36(80)$ & & - \\
\hline$\geqslant 1 S D$ & $46(66.7)$ & $9(20)$ & & - \\
\hline
\end{tabular}

Data presented as median (standard deviation), unless otherwise specified.

BACS = Brief Assessment of Cognition in Schizophrenia; CPMZ = chlorpromazine; PANSS = Positive and Negative Syndrome Scale; $\mathrm{SD}=$ standard deviation

$* p<0.05 ;{ }^{* *} p<0.01$.

Table 2 Allelic and genotypic frequencies of CNR1 and CNR2 gene polymorphisms

\begin{tabular}{|c|c|c|c|c|c|c|c|c|}
\hline SNP & $\mathrm{n}$ & Allele $f$ & $y(\%)$ & $p$-value & \multicolumn{3}{|c|}{ Genotypic frequency (\%) } & HWE \\
\hline \multirow{2}{*}{$\begin{array}{l}\text { CNR1 } \\
\quad \text { rs12720071 }\end{array}$} & & & & & & & & \\
\hline & & $T$ & $\mathrm{C}$ & & $\mathrm{T} / \mathrm{T}$ & $\mathrm{C} / \mathrm{T}$ & $\mathrm{C} / \mathrm{C}$ & \\
\hline Patients & 69 & $82(59)$ & $56(41)$ & & $17(25)$ & $48(69)$ & $4(6)$ & $<0.01$ \\
\hline Controls & 44 & $67(76)$ & $21(24)$ & $0.009 *$ & $27(61)$ & $13(30)$ & $4(9)$ & 0.21 \\
\hline \multirow{2}{*}{$\begin{array}{l}\text { CNR2 } \\
\quad \text { rs2229579 }\end{array}$} & & & & & & & & \\
\hline & & $\mathrm{G}$ & A & & $\mathrm{G} / \mathrm{G}$ & $\mathrm{G} / \mathrm{A}$ & $\mathrm{A} / \mathrm{A}$ & \\
\hline Patients & 68 & $113(83)$ & $23(17)$ & & $52(77)$ & $9(13)$ & $7(10)$ & $<0.01$ \\
\hline Controls & 45 & $84(93)$ & $6(7)$ & $0.024^{*}$ & $40(89)$ & $4(9)$ & $1(2)$ & 0.06 \\
\hline
\end{tabular}

CNR1 = cannabinoid receptor 1; CNR2 = cannabinoid receptor 2; HWE = Hardy-Weinberg equilibrium; SNP = single nucleotide polymorphisms.

$* p<0.025$ (corrected for multiple comparisons).

$\mathrm{p}<0.005$ ). For verbal fluency (Table 3), once again C/C patients scored significantly lower in the total verbal fluency test than $\mathrm{T}$ allele carriers (mean [standard error] = 12.2 [3.7] vs. 28.9 [1.3], $p<0.005$ ). For domains of attention/processing speed and reasoning/problem solving, an association with genotype was found in patients, but the difference was not significant after multiple test correction. Regarding global cognitive performance
(Table 3), C/C patients presented a mean cognitive performance of $-2.8 \mathrm{SD}$ vs. $-1.3 \mathrm{SD}$ for T allele carriers; this difference is equivalent to almost $1.5 \mathrm{SD}(95 \%$ confidence interval $[95 \% \mathrm{Cl}]-2.28$ to $-0.61, \mathrm{p}<0.005$, significant after correction for multiple comparisons). After controlling for these possible confounders, the association between genotype and working memory was lost $(p=0.2)$, whereas the association between the genotype 
Table 3 Cannabinoid receptor 1 (CNR1) rs12720071 polymorphism genotype and cognitive performance in patients with schizophrenia

\begin{tabular}{|c|c|c|c|c|c|}
\hline Cognitive domain/genetic model & $\mathrm{n}$ & Mean (SE) & Difference & $95 \% \mathrm{Cl}$ & $p$-value \\
\hline \multicolumn{6}{|l|}{ Working memory } \\
\hline \multicolumn{6}{|l|}{ Codominant } \\
\hline$T / T$ & 17 & $8.7(1.1)$ & 0 & & \\
\hline $\mathrm{C} / \mathrm{T}$ & 48 & $13.2(0.6)$ & 4.5 & 2.1 to 7 & \\
\hline $\mathrm{C} / \mathrm{C}$ & 4 & $8(3)$ & -0.7 & -5.5 to 4.1 & $0.00062^{\star \star}$ \\
\hline \multicolumn{6}{|l|}{ Dominant } \\
\hline$T / T$ & 17 & $8.7(1.1)$ & 0 & & \\
\hline $\mathrm{C} / \mathrm{T}-\mathrm{C} / \mathrm{C}$ & 52 & $12.8(0.6)$ & 4.1 & 1.6 to 6.6 & $0.00175^{\star \star}$ \\
\hline \multicolumn{6}{|l|}{ Recessive } \\
\hline $\mathrm{T} / \mathrm{T}-\mathrm{C} / \mathrm{T}$ & 65 & $12.1(0.6)$ & 0 & & \\
\hline $\mathrm{C} / \mathrm{C}$ & 4 & $8(3)$ & -4.1 & -8.9 to 0.8 & 0.10495 \\
\hline \multicolumn{6}{|l|}{ Overdominant } \\
\hline $\mathrm{T} / \mathrm{T}-\mathrm{C} / \mathrm{C}$ & 21 & $8.6(1)$ & 0 & & \\
\hline $\mathrm{C} / \mathrm{T}$ & 48 & $13.2(0.6)$ & 4.7 & 2.4 to 6.9 & $0.00012^{\star *}$ \\
\hline \multicolumn{6}{|l|}{ log-additive } \\
\hline $0,1,2$ & & & 2 & -0.1 to 4.2 & 0.0709 \\
\hline \multicolumn{6}{|l|}{ Motor speed } \\
\hline \multicolumn{6}{|l|}{ Codominant } \\
\hline $\mathrm{T} / \mathrm{T}$ & 17 & $51.6(4.7)$ & 0 & & \\
\hline $\mathrm{C} / \mathrm{T}$ & 48 & $48.8(2.4)$ & -2.8 & -12.5 to 6.8 & \\
\hline $\mathrm{C} / \mathrm{C}$ & 4 & $21(10.5)$ & -30.6 & -49.7 to -11.6 & $0.00802^{*}$ \\
\hline \multicolumn{6}{|l|}{ Dominant } \\
\hline $\mathrm{T} / \mathrm{T}$ & 17 & $51.6(4.7)$ & 0 & & \\
\hline $\mathrm{C} / \mathrm{T}-\mathrm{C} / \mathrm{C}$ & 52 & $46.7(2.5)$ & -4.9 & -15.1 to 5.2 & 0.34217 \\
\hline \multicolumn{6}{|l|}{ Recessive } \\
\hline $\mathrm{T} / \mathrm{T}-\mathrm{C} / \mathrm{T}$ & 65 & $49.6(2.1)$ & 0 & & \\
\hline $\mathrm{C} / \mathrm{C}$ & 4 & $21(10.5)$ & -28.6 & -46.1 to -11 & $0.0021^{\star *}$ \\
\hline \multicolumn{6}{|l|}{ Overdominant } \\
\hline $\mathrm{T} / \mathrm{T}-\mathrm{C} / \mathrm{C}$ & 21 & $45.8(5)$ & 0 & & \\
\hline $\mathrm{C} / \mathrm{T}$ & 48 & $48.8(2.4)$ & 3 & -6.5 to 12.6 & 0.5367 \\
\hline \multicolumn{6}{|l|}{ log-additive } \\
\hline $0,1,2$ & & & -9.2 & -17.4 to -1 & $0.03091^{*}$ \\
\hline \multicolumn{6}{|l|}{ Verbal fluency } \\
\hline \multicolumn{6}{|l|}{ Codominant } \\
\hline$T / T$ & 17 & $27.6(2.4)$ & 0 & & \\
\hline $\mathrm{C} / \mathrm{T}$ & 48 & $30.7(1.5)$ & 3 & -2.6 to 8.7 & \\
\hline $\mathrm{C} / \mathrm{C}$ & 4 & $12.2(3.7)$ & -15.4 & -26.6 to -4.2 & $0.00361^{\star *}$ \\
\hline \multicolumn{6}{|l|}{ Dominant } \\
\hline$T / T$ & 17 & $27.6(2.4)$ & 0 & & \\
\hline $\mathrm{C} / \mathrm{T}-\mathrm{C} / \mathrm{C}$ & 52 & $29.2(1.6)$ & 1.6 & -4.4 to 7.7 & 0.60125 \\
\hline \multicolumn{6}{|l|}{ Recessive } \\
\hline $\mathrm{T} / \mathrm{T}-\mathrm{C} / \mathrm{T}$ & 65 & $29.9(1.3)$ & 0 & & \\
\hline $\mathrm{C} / \mathrm{C}$ & 4 & $12.2(3.7)$ & -17.6 & -28 to -7.3 & $0.00138^{\star *}$ \\
\hline \multicolumn{6}{|l|}{ Overdominant } \\
\hline $\mathrm{T} / \mathrm{T}-\mathrm{C} / \mathrm{C}$ & 21 & $24.7(2.4)$ & 0 & & \\
\hline $\mathrm{C} / \mathrm{T}$ & 48 & $30.7(1.5)$ & 6 & 0.5 to 11.5 & $0.03693 *$ \\
\hline $\begin{array}{c}\text { log-additive } \\
0,1,2\end{array}$ & & & -2.5 & -7.5 to 2.5 & 0.33845 \\
\hline
\end{tabular}


Table 3 (continued)

\begin{tabular}{|c|c|c|c|c|c|}
\hline Cognitive domain/genetic model & $\mathrm{n}$ & Mean (SE) & Difference & $95 \% \mathrm{Cl}$ & $p$-value \\
\hline \multicolumn{6}{|l|}{ Global cognitive performance } \\
\hline \multicolumn{6}{|l|}{ Codominant } \\
\hline $\mathrm{T} / \mathrm{T}$ & 17 & $-1.6(0.2)$ & 0 & & \\
\hline $\mathrm{C} / \mathrm{T}$ & 48 & $-1.3(0.1)$ & 0.3 & -0.2 to 0.7 & \\
\hline $\mathrm{C} / \mathrm{C}$ & 4 & $-2.8(0.4)$ & -1.2 & -2.1 to -0.3 & $0.00244^{\star *}$ \\
\hline \multicolumn{6}{|l|}{ Dominant } \\
\hline $\mathrm{T} / \mathrm{T}$ & 17 & $-1.6(0.2)$ & 0 & & \\
\hline $\mathrm{C} / \mathrm{T}-\mathrm{C} / \mathrm{C}$ & 52 & $-1.4(0.1)$ & 0.2 & -0.3 to 0.6 & 0.5081 \\
\hline \multicolumn{6}{|l|}{ Recessive } \\
\hline $\mathrm{T} / \mathrm{T}-\mathrm{C} / \mathrm{T}$ & 65 & $-1.3(0.1)$ & 0 & & \\
\hline $\mathrm{C} / \mathrm{C}$ & 4 & $-2.8(0.4)$ & -1.4 & -2.3 to -0.6 & $0.0011^{\star *}$ \\
\hline \multicolumn{6}{|l|}{ Overdominant } \\
\hline $\mathrm{T} / \mathrm{T}-\mathrm{C} / \mathrm{C}$ & 21 & $-1.8(0.2)$ & 0 & & \\
\hline $\mathrm{C} / \mathrm{T}$ & 48 & $-1.3(0.1)$ & 0.5 & 0.1 to 1 & $0.02419 *$ \\
\hline \multicolumn{6}{|l|}{ log-additive } \\
\hline $0,1,2$ & & & -0.2 & -0.6 to 0.2 & 0.38594 \\
\hline
\end{tabular}

${ }^{*} p<0.05 ;{ }^{* *} p<0.005$ (corrected for multiple comparisons).

and motor speed $(p=0.01)$, verbal fluency $(p=0.01)$ and global cognitive performance $(p=0.004)$ remained significant. There was no association between the CNR1 rs12720071 polymorphism and cognitive performance in controls.

\section{Cannabinoid receptor 2 (CNR2) rs2229579 polymorphism and cognitive performance}

CNR2 rs2229579 (G > A) polymorphism was nominally associated with patient's performance in the working memory test. A/A patients had worse performance than $G$ allele carriers, but the difference was not significant after correction for multiple tests. There was no association between the CNR2 rs2229579 polymorphism and cognitive performance in controls.

\section{Discussion}

In the present study, patients presented a global mean cognitive performance approximately 1.5 SD below the normative sample, and significantly lower than the performance of controls. This is consistent with the literature, which shows cognitive performance on average 1 to 2 SD below healthy subjects in individuals with schizophrenia. ${ }^{13,48}$ Attention, motor speed, and global cognitive function were the most impaired in our sample. Metaanalyses point to a pattern of multiple deficits in individuals with schizophrenia, with the largest effect sizes found in episodic memory, attention, and information processing. ${ }^{49-51}$

There was a consistent association of CNR1 rs 12720071 polymorphism with the cognitive performance of patients. $\mathrm{C} / \mathrm{C}$ subjects had significantly lower performance on motor speed, verbal fluency (all of which were significant after controlling for multiple tests), attention/processing speed, and reasoning/problem solving (nominally significant) compared to T allele carriers. Regarding working memory, worse performance was paradoxically recorded in both
$\mathrm{C} / \mathrm{C}$ and $\mathrm{T} / \mathrm{T}$ individuals, while heterozygotes performed better in this domain. Nevertheless, a significant association with global cognitive performance showed that individuals homozygous for the variant $(\mathrm{C} / \mathrm{C})$ allele had a much lower overall cognitive performance than those with the $T$ allele.

Two studies assessed the possible influence of CNR1 variations on cognitive performance in individuals with schizophrenia. An interaction between polymorphism rs12720071 and brain volume and neurocognition has been evaluated, ${ }^{37}$ with results that are consistent with our findings. In that study, individuals with the $\mathrm{C}$ allele performed poorly on attention/processing speed and reasoning/problem solving tests. For the latter domain, the performance was even worse in patients carrying the variant allele and with heavy cannabis use. Patients with the $\mathrm{C}$ allele also had lower volumes of frontal, temporal, and total white matter, and there was an additive effect of the use of cannabis regarding the lower levels of parietal white matter. ${ }^{37}$ While our data corroborated a worse performance in $\mathrm{C} / \mathrm{C}$ allele carriers in attention/processing speed and reasoning/problem solving, our patients also performed poorly on working memory, motor speed, and verbal fluency tests. In a longitudinal study, the association of two different CNR1 polymorphisms (rs7766029 and rs12720071) with neurocognitive performance was assessed in patients with first-episode psychosis after 18 months of treatment. For rs $12720071, \mathrm{~T} / \mathrm{C}$ carriers had a negative effect (lower improvement over time) on language functions, which points in the same direction as our findings, but a positive effect on visuospatial executive functions (higher improvement over time). ${ }^{38}$

CB1R is the main cannabinoid receptor in the CNS and plays an important role in modulation of other neurotransmitter systems through short- and long-term synaptic plasticity. EcS, via CB1R, optimizes synaptic communication by eliminating information flow in specific synapses, contributing to a fine-tuning of information processing in 
neural circuits. ${ }^{52}$ The CB1R encoding gene (CNR1) is located in chromosome 6 (6q14-q15), with 3,732 SNPs identified in its structure. ${ }^{53}$ The rs12720071 polymorphism is a substitution of a thymine for a cytosine in the 3'- untranslated region (3'-UTR), which may have important functions in regulation of gene expression. ${ }^{54}$ No study to date has examined how this SNP could mediate the expression or function of $C N R 1$, but there is evidence that the genomic region surrounding this polymorphism could be a binding site of a transcription factor, ${ }^{55}$ "CCAAT/enhancerbinding protein beta" (C/EBP beta) $)^{56}$ that can regulate gene expression. ${ }^{57,58}$ Therefore, nucleotide substitution induced by this mutation could potentially modify the transcription factor binding site and thus alter CB1R expression, ${ }^{37}$ which could lead to changes in cannabinoid receptor-mediated control of information processing in neural circuits responsible for cognitive responses.

The association between CNR1 polymorphism and changes in working memory reported here is consistent with several lines of evidence. For instance, CB1R agonist delta-9-tetrahydrocabinol (THC) can induce working memory impairment in healthy controls, ${ }^{59}$ and THC is able to induce cognitive impairments similar to those of schizophrenia. ${ }^{60}$ Greater changes in brain structures related to working memory have been found in patients with schizophrenia and in cannabis users when compared to controls. ${ }^{61}$ Additionally, an association between protein expression of EcS components (CB2R and synthesis and degradation enzymes) and working memory was found in individuals with first-onset schizophrenia, ${ }^{62}$ while CNR1 rs1406977 genotypes have been associated with marijuana use and changes in prefrontal connectivity ${ }^{32}$ and activity, ${ }^{33}$ and worst working memory performance. Lastly, cannabis use has been observed to modify the relationship between endocannabinoid gene expression and the efficiency of information processing in working memory networks. Non-users had greater co-expression of a gene network that contains CNR1 and increased dorsolateral prefrontal efficiency. ${ }^{34}$ It has been proposed that under physiological conditions, EcS, via CB1R, modulates GABAergic neurotransmission of PFC interneurons, a process that could be disturbed by excessive and generalized agonism caused by exogenous cannabinoids. This could lead to dysfunctional hyperactivation of CB1Rs, and loss of modulation of glutamatergic neurons, with consequent disruption of dopamine release in dorsolateral prefrontal cortex (dIPFC) and impairment of working memory. ${ }^{63}$ Additionally, there is evidence of lower levels of CB1R mRNA in dIPFC of patients with schizophrenia. ${ }^{64}$

Changes in motor speed and verbal fluency, as well as their relation to EcS, might be better understood through their association with the speed of information processing domain. ${ }^{65}$ This cognitive ability, measured by how quickly an individual performs cognitive tasks, ${ }^{66}$ is a general measure of cognitive mechanisms that are used to support the fluent execution of perceptual, cognitive, and motor processes. ${ }^{67}$ It is known that the speed of information processing depends on white matter properties, ${ }^{68,69}$ and that its volume and integrity are globally related to this domain. ${ }^{66}$ Evidence suggests that endocannabinoids, via CB1R, could be involved in regulation of myelination in the developing ${ }^{70}$ and adult brain, ${ }^{71,72}$ stimulating myelin production by modulating progenitor cell survival, ${ }^{73}$ migration, and differentiation into oligodendrocytes. ${ }^{70}$ In addition, EcS plays a central role in cortico-limbic circuit maturation, supporting fundamental processes, such as inhibitory and excitatory neurotransmission balance. ${ }^{74}$ Activation of CB1R in glutamatergic neurons modulates GABAergic neurotransmission, which is critical for the developmental remodeling of inhibitory circuits during adolescence. ${ }^{75,76}$ Accordingly, previous research found that rs12720071 C allele carriers presented lower frontal, temporal, and total cerebral white matter. ${ }^{37}$

Our study has limitations. First, the size of our sample should be considered, especially when we subdivide the subjects into cognitive subgroups or in relation to less frequent genotypes. Consequently, we were unable to evaluate a possible interaction effect between genotype and cannabis use. Second, genotypic distribution in individuals with schizophrenia deviated from that expected by the HWE. In genetic association studies, HWE principles are applied to detect genotyping error and disease susceptibility loci. ${ }^{77}$ Typically, HWE does not need to hold for the case-group, since it represents a nonrandom selection of individuals based on a phenotype of interest (i.e., disease). Furthermore, HWE deviation has been proposed as a measure of disease association when analyzing the case group per se. ${ }^{78}$ Therefore, the validity of genetic association studies depends considerably on the use of appropriate controls and, theoretically, disease-free control groups from outbred populations should follow the HWE, as noted in our sample. ${ }^{79,80}$ Third, although controls did not report use of cannabis, it is not possible to guarantee they were not using it. Unfortunately, we did not measure urine levels of cannabis, which is a limitation of our work. Fourth, Brazilian populations present a high degree of miscegenation, ${ }^{81}$ a fact that may complicate population stratification. ${ }^{82}$ Besides that, we lack information about genetic ancestry in our sample. Finally, other potential limitations are those associated with an SNP-based analysis. ${ }^{83}$

In conclusion, our results are consistent with previous findings that point to the possible involvement of $C N R 1$ gene variations in the neurocognitive performance of individuals with schizophrenia. In particular, the association of a specific variation of CNR1 with cognitive performance in individuals with schizophrenia suggests the possible involvement of this variant in the pathogenesis of cognitive deficits. These findings may contribute to the understanding of the complex genetic determinants of cognitive deficits in schizophrenia, and can stimulate further efforts to replicate and expand the research.

\section{Acknowledgements}

This study was supported by grants from Coordenação de Aperfeiçoamento de Pessoal de Nível Superior (CAPES), Fundação de Amparo à Pesquisa de Minas Gerais (FAPEMIG) and Conselho Nacional de Desenvolvimento Científico e Tecnológico (CNPq). 


\section{Disclosure}

The authors report no conflicts of interest.

\section{References}

1 Tandon R, Nasrallah HA, Keshavan MS. Schizophrenia, 'just the facts' 4. Clinical features and conceptualization. Schizophr Res. 2009;110:1-23.

2 Kahn RS, Sommer IE, Murray RM, Meyer-Lindenberg A, Weinberger DR, Cannon TD, et al. Schizophrenia. Nat Rev Dis Primers. 2015;1:15067.

3 Insel TR. Rethinking schizophrenia. Nature. 2010;468:187-93.

4 Sullivan PF, Kendler KS, Neale MC. Schizophrenia as a complex trait: evidence from a meta-analysis of twin studies. Arch Gen Psychiatry. 2003;60:1187-92.

5 Gratten J, Wray NR, Keller MC, Visscher PM. Large-scale genomics unveils the genetic architecture of psychiatric disorders. Nat Neurosci. 2014;17:782-90.

6 Schizophrenia Working Group of the Psychiatric Genomics Consortium. Biological insights from 108 schizophrenia-associated genetic loci. Nature. 2014;511:421-7.

7 Henriksen MG, Nordgaard J, Jansson LB. Genetics of schizophrenia: overview of methods, findings and limitations. Front Hum Neurosci. 2017; $11: 322$

8 Tandon R, Keshavan MS, Nasrallah HA. Schizophrenia, 'just the facts': what we know in 2008. 2. Epidemiology and etiology. Schizophr Res. 2008;102:1-18.

9 Gottesman II, Gould TD. The endophenotype concept in psychiatry: etymology and strategic intentions. Am J Psychiatry. 2003;160:63645.

10 Bustamante ML, Herrera L, Gaspar PA, Nieto R, Maturana A, Villar $\mathrm{MJ}$, et al. Shifting the focus toward rare variants in schizophrenia to close the gap from genotype to phenotype. Am J Med Genet B Neuropsychiatr Genet. 2017;174:663-70.

11 Toulopoulou T, Picchioni M, Rijsdijk F, Hua-Hall M, Ettinger U, Sham $P$, et al. Substantial genetic overlap between neurocognition and schizophrenia: genetic modeling in twin samples. Arch Gen Psychiatry. 2007;64:1348-55

12 Gur RE, Calkins ME, Gur RC, Horan WP, Nuechterlein KH, Seidman $\mathrm{LJ}$, et al. The consortium on the genetics of schizophrenia: neurocognitive endophenotypes. Schizophr Bull. 2007;33:49-68.

13 Kahn RS, Keefe RS. Schizophrenia is a cognitive illness: time for a change in focus. JAMA Psychiatry. 2013;70:1107-12.

14 Green MF, Harvey PD. Cognition in schizophrenia: past, present, and future. Schizophr Res Cogn. 2014;1:e1-9.

15 Braff DL, Freedman R, Schork NJ, Gottesman II. Deconstructing schizophrenia: an overview of the use of endophenotypes in order to understand a complex disorder. Schizophr Bull. 2007;33:21-32.

16 Ferretjans R, Moreira FA, Teixeira AL, Salgado JV. The endocannabinoid system and its role in schizophrenia: a systematic review of the literature. Braz J Psychiatry. 2012;34 Suppl 2:S163-77.

17 Kano M, Ohno-Shosaku T, Hashimotodani Y, Uchigashima M, Watanabe M. Endocannabinoid-mediated control of synaptic transmission. Physiol Rev. 2009;89:309-80.

18 Basavarajappa BS, Nixon RA, Arancio O. Endocannabinoid system: emerging role from neurodevelopment to neurodegeneration. Mini Rev Med Chem. 2009;9:448-62.

19 Melis M, Pistis M. Hub and switches: endocannabinoid signalling in midbrain dopamine neurons. Philos Trans R Soc B Biol Sci. 2012;367:3276-85.

$20 \mathrm{Lu} \mathrm{HC}$, MacKie K. An introduction to the endogenous cannabinoid system. Biol Psychiatry. 2016;79:516-25.

21 Castillo PE, Younts TJ, Chávez AE, Hashimotodani Y. Endocannabinoid signaling and synaptic function. Neuron. 2012;76:70-81.

22 Miller LK, Devi LA. The highs and lows of cannabinoid receptor expression in disease: mechanisms and their therapeutic implications. Pharmacol Rev. 2011;63:461-70.

23 Zhang PW, Ishiguro H, Ohtsuki T, Hess J, Carillo F, Walther D, et al. Human cannabinoid receptor $1: 5^{\prime}$ exons, candidate regulatory regions, polymorphisms, haplotypes and association with polysubstance abuse. Mol Psychiatry. 2004;9:916-31.
24 Onaivi ES, Ishiguro H, Gong JP, Patel S, Meozzi PA, Myers L, et al. Brain neuronal CB2 cannabinoid receptors in drug abuse and depression: from mice to human subjects. PLoS One. 2008;3:e1640.

25 Liu QR, Pan CH, Hishimoto A, Li CY, Xi ZX, Llorente-Berzal A, et al. Species differences in cannabinoid receptor 2 (CNR2 gene): identification of novel human and rodent CB2 isoforms, differential tissue expression and regulation by cannabinoid receptor ligands. Genes Brain Behav. 2009;8:519-30.

26 Johnson JP, Muhleman D, MacMurray J, Gade R, Verde R, Ask M, et al. Association between the cannabinoid receptor gene (CNR1) and the P300 event-related potential. Mol Psychiatry. 1997;2:169-71.

27 Stadelmann AM, Juckel G, Arning L, Gallinat J, Epplen JT, Roser P. Association between a cannabinoid receptor gene (CNR1) polymorphism and cannabinoid-induced alterations of the auditory eventrelated P300 potential. Neurosci Lett. 2011;496:60-4.

28 Ruiz-Contreras AE, Carrillo-Sánchez K, Ortega-Mora I, BarreraTlapa MA, Román-López TV, Rosas-Escobar CB, et al. Performance in working memory and attentional control is associated with the rs2180619 SNP in the CNR1 gene. Genes Brain Behav. 2014;13: 173-8.

29 Ruiz-Contreras AE, Delgado-Herrera M, García-Vaca PA, AlmeidaRosas GA, Soria-Rodríguez G, Soriano-Bautista A, et al. Involvement of the AATn polymorphism of the CNR1 gene in the efficiency of procedural learning in humans. Neurosci Lett. 2011;494:202-6.

30 Ruiz-Contreras AE, Carrillo-Sánchez K, Gómez-López N, VadilloOrtega F, Hernández-Morales S, Carnevale-Cantoni A, et al. Working memory performance in young adults is associated to the AATn polymorphism of the CNR1 gene. Behav Brain Res. 2013;236:62-6.

31 Ruiz-Contreras AE, Román-López TV, Caballero-Sánchez U, RosasEscobar CB, Ortega-Mora EI, Barrera-Tlapa MA, et al. Because difficulty is not the same for everyone: the impact of complexity in working memory is associated with cannabinoid 1 receptor genetic variation in young adults. Memory. 2017;25:335-43.

32 Colizzi M, Fazio L, Ferranti L, Porcelli A, Masellis R, Marvulli D, et al. Functional genetic variation of the cannabinoid receptor 1 and cannabis use interact on prefrontal connectivity and related working memory behavior. Neuropsychopharmacology. 2015;40:640-9.

33 Taurisano P, Antonucci LA, Fazio L, Rampino A, Romano R, Porcelli $A$, et al. Prefrontal activity during working memory is modulated by the interaction of variation in CB1 and COX2 coding genes and correlates with frequency of cannabis use. Cortex. 2016;81:231-8.

34 Taurisano P, Pergola G, Monda A, Antonucci LA, Di Carlo P, Piarulli $F$, et al. The interaction between cannabis use and a CB1-related polygenic co-expression index modulates dorsolateral prefrontal activity during working memory processing. Brain Imaging Behav. 2021;15:288-99.

35 Krebs MO, Morvan Y, Jay T, Gaillard R, Kebir O. Psychotomimetic effects at initiation of cannabis use are associated with cannabinoid receptor 1 (CNR1) variants in healthy students. Mol Psychiatry. 2014;19:402-3.

36 Legge SE, Jones HJ, Kendall KM, Pardiñas AF, Menzies G, BracherSmith $M$, et al. Association of genetic liability to psychotic experiences with neuropsychotic disorders and traits. JAMA Psychiatry. 2019;76:1256-65.

37 Ho BC, Wassink TH, Ziebell S, Andreasen NC. Cannabinoid receptor 1 gene polymorphisms and marijuana misuse interactions on white matter and cognitive deficits in schizophrenia. Schizophr Res. 2011;128:66-75.

38 Rojnic Kuzman M, Kuharic DB, Ganoci L, Makaric P, Kekin I, Gajsak LR, et al. Association of CNR1 genotypes with changes in neurocognitive performance after eighteen-month treatment in patients with first-episode psychosis. Eur Psychiatry. 2019;61:88-96.

39 Associação Americana de Psiquiatria. Manual Diagnóstico e Estatístico de Transtornos Mentais, $4^{\mathrm{a}}$ edição (DSM-IV-TM). Porto Alegre: Artes Médicas2002.

40 Sheehan DV, Lecrubier Y, Sheehan KH, Amorim P, Janavs J, Weiller E, et al. The Mini-International Neuropsychiatric Interview (M.I.N.I.): the development and validation of a structured diagnostic psychiatric interview for DSM-IV and ICD-10. J Clin Psychiatry. 1998;59 Suppl 20:22-33; quiz 34-57.

41 Amorim $\mathrm{P}$. Mini International Neuropsychiatric Interview (MINI): validação de entrevista breve para diagnóstico de transtornos mentais. Rev Bras Psiquiatr. 2000;22:106-15. 
42 Kay SR, Fiszbein A, Opler LA. The positive and negative syndrome scale (PANSS) for schizophrenia. Schizophr Bull. 1987;13:261-76.

43 Keefe RS, Goldberg TE, Harvey PD, Gold JM, Poe MP, Coughenour L. The brief assessment of cognition in schizophrenia: reliability, sensitivity, and comparison with a standard neurocognitive battery. Schizophr Res. 2004;68:283-97.

44 Araújo GE, de Resende CB, Cardoso AC, Teixeira AL, Keefe RS, Salgado JV. Validity and reliability of the Brazilian Portuguese version of the BACS (Brief Assessment of Cognition in Schizophrenia). Clinics (Sao Paulo). 2015;70:278-82.

45 Suárez-Pinilla P, Roiz-Santiañez R, de la Foz V, Guest PC, AyesaArriola $R$, Córdova-Palomera $A$, et al. Brain structural and clinical changes after first episode psychosis: focus on cannabinoid receptor 1 polymorphisms. Psychiatry Res. 2015;233:112-9.

46 IBM Corp. Released 2011. IBM SPSS Statistics for Windows, Version 20.0. Armonk: IBM Corp.

47 R Core Team. R: a language and environment for statistical computing. Vienna: R Foundation for Statistical Computing; 2013. www. R-project.org/

48 Dickinson D, Ramsey ME, Gold JM. Overlooking the obvious: a meta-analytic comparison of digit symbol coding tasks and other cognitive measures in schizophrenia. Arch Gen Psychiatry. 2007;64: 532-42.

49 Fioravanti M, Carlone O, Vitale B, Cinti ME, Clare L. A meta-analysis of cognitive deficits in adults with a diagnosis of schizophrenia. Neuropsychol Rev. 2005;15:73-95.

50 Heinrichs RW, Zakzanis KK. Neurocognitive deficit in schizophrenia: a quantitative review of the evidence. Neuropsychology. 1998;12: 426-45.

51 Mesholam-Gately RI, Giuliano AJ, Goff KP, Faraone SV, Seidman LJ. Neurocognition in first-episode schizophrenia: a meta-analytic review. Neuropsychology. 2009;23:315-36.

52 de Fonseca FR, Del Arco I, Bermudez-Silva FJ, Bilbao A, Cippitelli A, Navarro M. The endocannabinoid system: physiology and pharmacology. Alcohol Alcohol. 2005;40:2-14.

53 Center for Biotechnology Information (US), N. The variation viewer: a navigator for dbSNP, dbVar and ClinVar [Internet]. 2014 [cited 2021 Mar 16]. www.ncbi.nlm.nih.gov/books/NBK208514/

54 Barrett LW, Fletcher S, Wilton SD. Regulation of eukaryotic gene expression by the untranslated gene regions and other non-coding elements. Cell Mol Life Sci. 2012;69:3613-34.

55 Heinemeyer T, Wingender E, Reuter I, Hermjakob H, Kel AE, Kel OV, et al. Databases on transcriptional regulation: TRANSFAC, TRRD and COMPEL. Nucleic Acids Res. 1998;26:362-7.

56 Akira S, Isshiki H, Sugita T, Tanabe O, Kinoshita S, Nishio Y, et al. A nuclear factor for IL-6 expression (NF-IL6) is a member of a C/EBP family. EMBO J. 1990;9:1897-906.

57 Ménard C, Hein P, Paquin A, Savelson A, Yang XM, Lederfein D, et al. An essential role for a MEK-C/EBP pathway during growth factor-regulated cortical neurogenesis. Neuron. 2002;36:597-610.

58 Pulido-Salgado M, Vidal-Taboada JM, Saura J. C/EBP $\beta$ and C/EBP $\delta$ transcription factors: basic biology and roles in the CNS. Prog Neurobiol. 2015;132:1-33.

59 Bossong MG, Jansma JM, van Hell HH, Jager G, Oudman E, et al. Effects of $\Delta 9$-tetrahydrocannabinol on human working memory function. Biol Psychiatry. 2012;71:693-9.

60 Solowij N, Michie PT. Cannabis and cognitive dysfunction: parallels with endophenotypes of schizophrenia? J Psychiatry Neurosci. 2007;32:30-52.

61 Smith MJ, Cobia DJ, Wang L, Alpert KI, Cronenwett WJ, Goldman $\mathrm{MB}$, et al. Cannabis-related working memory deficits and associated subcortical morphological differences in healthy individuals and schizophrenia subjects. Schizophr Bull. 2014;40:287-99.

62 Bioque M, Cabrera B, García-Bueno B, Mac-Dowell K, Torrent C, Saiz PA, et al. Dysregulated peripheral endocannabinoid system signaling is associated with cognitive deficits in first-episode psychosis. J Psychiatr Res. 2016;75:14-21.
63 Skosnik PD, Ranganathan M, D'Souza DC. Cannabinoids, working memory, and schizophrenia. Biol Psychiatry. 2012;71:662-3.

64 Eggan SM, Hashimoto T, Lewis DA. Reduced cortical cannabinoid 1 receptor messenger RNA and protein expression in schizophrenia. Arch Gen Psychiatry. 2008;65:772-84.

65 Nuechterlein KH, Barch DM, Gold JM, Goldberg TE, Green MF Heaton RK. Identification of separable cognitive factors in schizophrenia. Schizophr Res. 2004;72:29-39.

66 Magistro D, Takeuchi H, Nejad KK, Taki Y, Sekiguchi A, Nouchi R, et al. The relationship between processing speed and regional white matter volume in healthy young people. PLoS One. 2015;10: e0136386.

67 Lezak MD, Howieson DB, Bigler ED, Tranel D. Neuropsychological assessment. Oxford: Oxford University; 2012.

68 Borghesani PR, Madhyastha TM, Aylward EH, Reiter MA, Swarny $\mathrm{BR}$, Schaie KW, et al. The association between higher order abilities, processing speed, and age are variably mediated by white matter integrity during typical aging. Neuropsychologia. 2013;51:1435-44.

69 Jacobs HI, Leritz Ec, Williams VJ, Van Boxtel MP, van der Elst W, Jolles $\mathrm{J}$, et al. Association between white matter microstructure, executive functions, and processing speed in older adults: the impact of vascular health. Hum Brain Mapp. 2013;34:77-95.

70 Arévalo-Martín Á, García-Ovejero D, Rubio-Araiz A, Gómez O, Molina-Holgado F, Molina-Holgado E. Cannabinoids modulate Olig2 and polysialylated neural cell adhesion molecule expression in the subventricular zone of post-natal rats through cannabinoid receptor 1 and cannabinoid receptor 2. Eur J Neurosci. 2007;26:1548-59.

71 Scotter EL, Abood ME, Glass M. The endocannabinoid system as a target for the treatment of neurodegenerative disease. $\mathrm{Br} J$ Pharmacol. 2010;160:480-98.

72 Kittler JT, Grigorenko EV, Clayton C, Zhuang SY, Bundey SC, Trower MM, et al. Large-scale analysis of gene expression changes during acute and chronic exposure to [Delta]9-THC in rats. Physiol Genomics. 2000;3:175-85.

73 Molina-Holgado E, Vela JM, Arévalo-Martín A, Almazán G, MolinaHolgado F, Borrell J, et al. Cannabinoids promote oligodendrocyte progenitor survival: involvement of cannabinoid receptors and phosphatidylinositol-3 kinase/Akt signaling. J Neurosci. 2002;22:9742-53.

74 Meyer HC, Lee FS, Gee DG. The role of the endocannabinoid system and genetic variation in adolescent brain development. Neuropsychopharmacology. 2018;43:21-33.

75 Fortin DA, Levine ES. Differential effects of endocannabinoids on glutamatergic and GABAergic inputs to layer 5 pyramidal neurons. Cereb Cortex. 2007;17:163-74.

76 Tseng KY, Chambers RA, Lipska BK. The neonatal ventral hippocampal lesion as a heuristic neurodevelopmental model of schizophrenia. Behav Brain Res. 2009;204:295-305.

77 Ryckman K, Williams SM. Calculation and use of the Hardy-Weinberg model in association studies. Curr Protoc Hum Genet. 2008; Chapter 1: Unit 1.18.

78 Namipashaki A, Razaghi-Moghadam Z, Ansari-Pour N. The essentiality of reporting Hardy-Weinberg equilibrium calculations in population-based genetic association studies. Cell J. 2015;17:187-92.

79 Salanti G, Amountza G, Ntzani EE, Ioannidis JP. Hardy-Weinberg equilibrium in genetic association studies: An empirical evaluation of reporting, deviations, and power. Eur J Hum Genet. 2005;13:840-8.

80 Balding DJ. A tutorial on statistical methods for population association studies. Nat Rev Genet. 2006;7:781-91.

81 Giolo SR, Soler JM, Greenway Sc, Almeida MA, de Andrade M, Seidman JG, et al. Brazilian urban population genetic structure reveals a high degree of admixture. Eur J Hum Genet. 2012;20:111-6.

82 Gomes KF, Santos AS, Semzezem C, Correia MR, Brito LA, Ruiz $\mathrm{MO}$, et al. The influence of population stratification on genetic markers associated with type 1 diabetes. Sci Rep. 2017;7:43513.

83 Kendler KS. What psychiatric genetics has taught us about the nature of psychiatric illness and what is left to learn. Mol Psychiatry. 2013;18:1058-66. 